\title{
Emerging Health Problems among Reproductive Mothers in Abakaliki Urban of Ebonyi State: Implication for Sustainable Development
}

\author{
Nkiru Edith Obande-Ogbuinya, MaryJoy Umoke*, Amari-Omaka L.N., Aleke C.O., Omeje C. B., Eunice Afoke, \\ Chinyere Alo, Chibuzo Uzoho, Jude Nwafor, John Onwe and Pat Ngwakwe
}

Physical and Health Education Department, Alex Ekwueme-Federal University Ndufu Alike Ikwo, Nigeria

Submission: February 03, 2020; Published: February 14, 2020

*Corresponding author: MaryJoy Umoke, Physical and Health Education Department, Alex Ekwueme-Federal University Ndufu Alike Ikwo, Nigeria

\begin{abstract}
Reproductive women are currently faced with a lot of health challenges which can be life threatening leading to high maternal morbidity and mortality thus, defeating one of the sustainable development goals (SDGs) of reducing global maternal mortality ratio to less than 70 per 100,000 live births. This study investigated the emerging health problems among reproductive mothers in Abakaliki urban of Ebonyi State. The descriptive Survey research design was adopted using a population of all reproductive mothers in Abakaliki Urban of Ebonyi State. Samples of 150 pregnant and nursing mothers respectively were selected through purposive sampling method. The Instrument for data collection was a self-constructed health problem among reproductive mothers' questionnaire (HPARMQ). Results of the study revealed physical, social and economic health problems being experienced by the reproductive mothers. Age $(\mathrm{p}=0.43)$, location $(\mathrm{p}=0.704)$ and parity $(0.276)$ are not significantly associated with high health problems during pregnancy. The study concluded that reproductive mothers in Abakaliki Urban had physical, social and economic health problems bordering their lives. These call for quick and urgent health education intervention and treatment for the women to avert further spread and danger posed by the health problems. The study recommended among others that government at all levels in collaboration with the ministry of health should organize periodic health education seminars for reproductive mothers in order to sensitize them concerning the prevailing health problems, prevention and control for their optimal health that wi1ll contribute to National growth and development.
\end{abstract}

Keywords: Physical; Social and economic health Problems; Selected reproductive mothers; Abakaliki urban

Abbreviations: HPARMQ: Health Problems among Reproductive Mothers' Questionnaire; WHO: World Health Organization; STDs: Sexually Transmitted Diseases; HIV: Human Immunodeficiency Virus; AIDS: Acquired Immune deficiency Syndrome; PCOS: Polycystic Ovary Syndrome; GDP: Gross Domestic Product; PP: Parish Priest

\section{Introduction}

Globally, research findings indicate that 535,900 women die from pregnancy and birth related causes in 2005. Among these women of reproductive age, about 36 percent of their healthy years are lost to reproductive health problems such as unregulated fertility, maternal deaths morbidity and STDs, HIV/AIDS [1]. Reproductive mothers can be described as pregnant/expecting or nursing mothers. They can also be called reproductive women [2]. These groups of women are faced with a lot of health problems in the course of pregnancy, through childbirth to nursing period and sometimes, beyond. More often than not, they are confronted with health challenges that may be life threatening and capable of impeding the women's daily tasks and safe motherhood consisting in maternal mortality or morbidity due to preventable pregnancy and childbirth related causes [3]. The relevance and indispensable roles of a healthy mother in the society cannot be overlooked.
In addition to her role in procreation, she trains her children to become ethical, able, resilient, and moral human beings [4]. She also has one of the most influential and important jobs in the world and one of the most difficult [5]. These include being a chef, housekeeper, conflict resolver, event planner, chauffeur, laundry, Counsellor, finance manager, health care provider, activities director, world changer among others. In the event of any unforeseen health problem, the various spheres of life she manages are also challenged. Suffix this to say that reproductive women need optimal health care in order to be able to carry out their everyday routines, sexual and reproductive functions and to be able to do them safely and successfully [6]. Such optimal health cares can be achieved only when the health problems confronting the women are known and addressed using appropriate health intervention strategy. Some of the women top emerging health 


\section{Global Journal of Reproductive Medicine}

problems include health problems such as sexual dysfunction, endometriosis, uterine fibroids, gynecological cancer and HIV/ AIDS, intestinal cystitis, polycystic ovary Syndrome (PCOS), sexually transmitted diseases, sexual violence, painful sex, lack of interest in sex, pelvic health disorders, unsatisfying sex, depression and ectopic pregnancy. Others are morning sickness, anaemia, back ache, widowhood, domestic violence, anxiety, stress, divorce, fear, restlessness, poverty, unemployment among others [7]. Some of the problems as stated can be grouped as physical health problems, social health problems and economic health problems. Physical health problems means living with or experiencing a chronic illness or condition that can result in many adjustments and changes such as loss of independence and not being able to do all activities one is used to doing and enjoying. These may include post-partum anxiety and depression [8]. Poor physical health can lead to an increased risk of developing mental health problems. During pregnancy, symptoms and complications can range from mild and annoying discomforts to severe sometimes life-threatening illnesses. Physical health problem during pregnancy may include physical conditions capable of affecting the health of the mother or the baby [7]. They may be minor and mild and not progress or they may be major and harmful to the mother or her baby. Some of these physical health problems are anemia, morning sickness, cramp, urinary tract infections causing pain or burning urinating, fever, tiredness or shakiness, urge to urinate often, pressure in the lower abdomen, urine that smells bad, nausea or back pains. Others are gestational diabetes mellitus, hypertension, obesity and weight gain, infections with HIV, viral hepatitis, STDs, tuberculosis and hyperemesis [7]. WHO reported physical health problem encompassing sexual and reproductive health problems as being responsible for one third of health issues for women between the ages of 15 and 44 years [1]? About $70 \%$ of white women and $80 \%$ of African American women develop uterine fibroids, a physical health problem. Also, an estimated 13.5 million women in the baby boomer generation have stress urinary incontinence. Nearly $40 \%$ of women aged 45-60 experience heavy menstrual periods in Italy [9]. The physical health problems are sometimes manifested more in one prevailing condition of the mother than the other. For instance [10] found that apart from pregnant mothers, nursing mothers also experience some physical health problems after childbirth. These may include pain with vaginal delivery, Pains at the incision site of caesarean sections. Some nursing mothers also experience swollen, lumpy, hard or painful or engorged breasts. There may be incidence of pain with breast feeding, infection at the surgical site of a c-section or a tear in the perineum, post-partum infections can also appear in the uterus, bladder or kidneys. However, Baylor and White pointed out that the infections are uncommon unless in cases of prolonged labour or prolonged rupture of membranes, a prolapsed (whereby the bladder, uterus, or bowel protrudes into the vagina) can be experienced by a new mother. Also, some nursing mothers can be notoriously tired (exhaustion). And there can also be cases of urinary incontinence common for 6 months or longer post-delivery. However, pelvic-floor physical therapy can be of help $[10,11]$.

In as much as reproductive women 's health is affected by their biology as seen in physical health problems, it is also affected by social conditions such as poverty, employment and family responsibilities leading to social health problems and these aspects should not be over shadowed [12]. Social health problems of reproductive mothers refer to social diseases that impact on women's physical, mental or social health. A major burden of the social health problems in reproductive women is related to their reproductive function and reproductive system, and the way society treats or mistreats them. Some of these social health problems may include female genital mutilation, sexual abuse and domestic violence [6,13]. Worldwide, about $10 \%$ of pregnant women and $13 \%$ of nursing mothers experience depression. It is higher in the developing countries with $15.6 \%$ during pregnancy and $19.8 \%$ after childbirth. In severe cases, the suffering may be too much that the mother may even commit suicide. Nevertheless, such mental and social disorders are treatable. Effective interventions can be delivered by well-trained non-specialist health providers [1]. On economic health problem, Blog Network [12] as well identified poverty, employment and family responsibilities as economic health problems. WHO [14] posited that with economic health problem, there continues to be a large disparity in maternal and child health indicators between high- and low-income countries? The highest levels of mother and child health can be found in European and higher income countries in Asia. Most of the countries with the highest mortality rates are those experiencing war and conflict. Almost all $99 \%$ of maternal deaths occur in low-income countries with the highest maternal deaths in African and poorer parts of Asia [14]. Two countries India and Nigeria account for a third of global maternal deaths. The highest infant mortality rates are also found in the same countries with maternal deaths [15]. Blog Network [12] revealed that women have traditionally been disadvantaged in terms of economic and social status and power which in turn reduces their access to the necessities of life including health care. Mcbarnette [16] held that health status of women declines as their socio-economic status including income, declines. Mcbannette further pointed out that relationship existed between poverty and several indicators of reproductive health status of women. A study [17] indicated a crucial role of economic factor in influencing the Polish women's health. It was found by the same study that reproductive women whose financial position was poor indicated more likelihood to assess their health as less than good to suffer from respiratory and circulatory system's diseases.

They also reported more neurotic problems. Other indicators of poor economic health of the mothers were lack of employment and low educational level especially among young reproductive mothers [18] recorded a positive and significant relationship 


\section{Global Journal of Reproductive Medicine}

between income of Pakistan women and their health. Be it as it may, with the unveiling of various prevailing health problems among reproductive mothers as viewed worldwide, in Africa and in a neighboring Enugu state, it is not out of place to determine emerging health problems among the selected reproductive mothers in Abakaliki Urban of Ebonyi State which harbors a significant population of reproductive mothers in active workforce. They were purposively selected from the catholic Christian denomination given to the large number of reproductive women that can be found among them. This may not be unconnected with the church's permissive attitude to childbearing devoid of artificial birth controls. Nevertheless, certain sociodemographic variables have been associated with women's health problems. They include age, parity and location getting older as it concerns age, can bring on health problems as a woman's body changes. Some medical conditions become more common and more serious as she goes up [19]. The risk for chronic diseases and other health problems increases with age. The problem varies however among women. Women in their 40s are more at risk for breast, ovarian and endometrial cancers [20]. Another investigation [21] revealed significant association of advanced maternal age with high maternal morbidity and infant mortality. No significant association was found between parity and women's health problems. Result of the study that investigated relationship between parity and physical health are less consistent. High parity was found to be detrimental to physical health. In some other studies, no relationship was found [22]. Parity was also associated with the presence of certain problems in the postpartum period. On relationship of location with women's health problem, rural women tend to have poorer health outcomes and also have limited access to health care than urban women. It can be attributed to restricted number of health care providers for the women [23]. What do all these imply for sustainable development? Sustainable development entails development that measures up with the needs of the present without compromising the ability of future generations to meet their own need [24]. Meeting the reproductive women's health needs if urgently tackled, cannot in any way disrupt or impede health of future mothers. Such attempt shall rather improve and lead to overall health development of the nation. Good health usually facilitates development while development often promoted improved health. While improved health may be a prerequisite for development, some behavioral determinants like attitude, environment and people's lifestyles as well as consumption patterns can impede the sustainability of the development process in the longer-term. Equally, development which is economically desirable e.g. in agriculture and industry, may have harmful consequences for health and the environment [24]. The link between health, poverty reduction and long term economic growth are powerful much stronger than is generally understood. The burden of disease in some Su-Saharan Africa, stands as a stark barrier to economic growth and therefore must be addressed as a central component of any comprehensive development strategy.

Malaria alone is estimated to slow economic growth in Africa up to $1.3 \%$ each year. The situation would probably have raised Africa's GDP 100 billion higher if malaria had been tackled 30 years ago, when effective control measures first became available. Even today, half a billion cases of malaria each year lead to loss of several bellion days of productive work [25]. Regardless of what the result of the study may be, with the result of the study, best approach and intervention shall be mounted taking into consideration with particular emphasis on age, parity and location of the women. This in effect, would curtail further hindrance to the women's health and smooth motherhood. Given to the status of mothers in developing countries, Nigeria inclusive with its component States of which Ebonyi state is one, a mother's death is much more than an emotional crisis, often leading to long term social and economic breakdown both for her immediate family and the wider community [26]. These then imply a sound health education for reproductive mothers for enhanced health promotion, maintenance and longevity. Health education refers to any combination of learning experiences designed to help individuals and communities improve their health by increasing their knowledge or influencing their attitudes [1]. Through health education, health behaviors of the mothers will be positively enhanced and influenced as well as their living and working conditions. There will be a positive change in their general knowledge, attitude and practice with regards to the various health problems and their solutions. Nevertheless, the muchneeded intervention cannot happen without determining the emerging health problems as it concerns the reproductive women and also determining the association of the independent variables of age, parity and location with the health problems of the women. These in the main, necessitated the present investigation.

\section{Materials and Methods}

The study adopted the descriptive survey research design. According to Iwuagwu and Ofuebe [27] it was recognized Nworgu [28] as appropriate for describing situations as they exist in their natural setting and determines relationships that exist between specific events. The population comprised all pregnant and nursing mothers in Abakaliki urban of Ebonyi State. A sample of 150 pregnant and nursing mothers was picked respectively through purposive sampling technique involving the use of 5 out of 7 catholic parishes in Abakaliki urban. It was due to their locations in densely populated areas and high attendance by people of the denomination. Using simple random sampling technique, 30 pregnant and 30 nursing mothers were picked from each of the chosen parishes leading to a total of 150 pregnant mothers and 150 nursing mothers selected for the study. In order to gain access to the study population, consent was first sought through consent letters from the parish priests (PPs) of the parishes involved prior to the time for data collection. They gave their consents and with the assistance of the women leaders, the instrument was shared 


\section{Global Journal of Reproductive Medicine}

among the chosen reproductive mothers on the day of their general meetings. The items in the instrument were interpreted to the illiterate ones also by these women leaders acting as research assistants. On completion, the instruments were collected back immediately, and this action ensured 100 per cent return rate. The Instrument was a self-constructed health problem among reproductive mothers' questionnaire (HPARMQ). It was in 6 sections with each representing the 6 variables of the study having a total of 72 items. The responses were on 2 points rating of yes and No. The instrument was given face and content validation by 3 experts in the department of Human kinetics and health education, Ebonyi State University, Abakaliki.
The corrected version of the instrument was given to reproductive women in a Presbyterian church and using Cronbach alpha test of reliability, a reliability coefficient of 0.74 was established. This was high enough considering [29] acceptance of instrument with reliability coefficient of 0.60 and above as good instrument. The completed copies of the questionnaire were coded and analysed using logistic regression analysis to answer the 6 research questions. Health problems with scores above $50 \%$ were considered major emerging health problems while those with score below $40 \%$ were considered minor emerging health problems.

\section{Results and Discussion}

Table 1: Distribution of Physical Health Problems among Pregnant Mothers in Abakaliki Urban of Ebonyi State.

\begin{tabular}{|c|c|c|}
\hline Physical Health Problems & No of Respondents & Percentage \\
\hline Abnormal vaginal discharge & 109 & $72.70 \%$ \\
\hline Abnormal Vaginal Itching & 106 & $70.70 \%$ \\
\hline Morning sickness & 101 & $67.30 \%$ \\
\hline Fatigue & 92 & $61.30 \%$ \\
\hline Itchy belly & 92 & $61.30 \%$ \\
\hline Premature labor & 82 & $54.70 \%$ \\
\hline Back ache & 78 & $52.00 \%$ \\
\hline Pica (strive for strange food) & 73 & $48.70 \%$ \\
\hline Indigestion & 69 & $46.00 \%$ \\
\hline High blood pressure & 65 & $43.30 \%$ \\
\hline Infections e.g. reburial, chicken pox, whooping cough & 63 & $42.00 \%$ \\
\hline Malnutrition & 59 & $39.30 \%$ \\
\hline Abdominal discomfort & 55 & $36.70 \%$ \\
\hline Stretch marks & 53 & $35.30 \%$ \\
\hline Pre-eclamsia & 52 & $34.70 \%$ \\
\hline Placental retention & 51 & $34.00 \%$ \\
\hline Constipation & 46 & $30.70 \%$ \\
\hline Cancer of the breast, cervical, uretus, ovary etc. & 45 & $30.00 \%$ \\
\hline Heart born & 43 & $28.70 \%$ \\
\hline Diabeted in pregnancy & 38 & $25.30 \%$ \\
\hline Anaemia & 36 & $24.00 \%$ \\
\hline Obesity & 35 & $23.30 \%$ \\
\hline Hemorrhoids & 35 & $23.30 \%$ \\
\hline Ectopic pregnancy & 33 & $22.00 \%$ \\
\hline Eclamsia & 27 & $18.00 \%$ \\
\hline Cramp & 26 & $17.30 \%$ \\
\hline Oedema & 22 & $14.70 \%$ \\
\hline HIV / AIDS & 14 & $9.30 \%$ \\
\hline
\end{tabular}

Result in Table 1 shows the distribution of physical health problems faced by selected pregnant mothers in Abakaliki Urban of Ebonyi State. The major physical health problems that affects more than $50 \%$ of the pregnant mothers are, "Abnormal vaginal 


\section{Global Journal of Reproductive Medicine}

discharge" 109 (72.7\%), "Abnormal Vaginal Itching” 106 (70.1\%), "Morning sickness" 101 (67.3\%), "Fatigue" 92 (61.3\%), "Itchy belly" 92 (61.3\%), "Premature labour" 82 (54.7\%), and "Back ache" 78 (52.0\%). Others that are above $40 \%$ physical problems experienced by pregnant mothers include, "Pica (strive for strange food)" 73 (48.7\%), "Indigestion" 69 (46.0\%), "High blood pressure" 65 (43.3\%) and "Infections e.g. reburial, chicken pox, whooping cough" 63 (42.0\%). However, the least physical health problem affecting below $20 \%$ of the pregnant mothers are HIV/ AIDS 14 (9.3\%), Oedema 22 (14.7\%), Cramp 26 (17.3\%), and Eclamsia. Within the group, further logistic regression analysis indicated $0-49 \%$ of the pregnant women with low physical health problem were $107(71.3 \%$ ) while $50 \%$ and above of the women had high physical health problem 43 (28.7\%) From the result in
Table 2 it goes to explain the emerging cases of physical health problems in the lives of the pregnant mothers. The result of the study was in line with [27] who found that $56.5 \%$ of pregnant women in their study area indicated physical health problems such as anaemia, nausea, vomiting, oedema, waist pain among others. The findings according to [27] were also in line with [30] that nearly 75 per cent of all pregnant women experience back ache, depression, anaemia and increased breathlessness [31] also found that nausea and back ache were the most commonly reported major physical health problems of pregnant women. The result did not come as a surprise. It could mean that the physical health problems are normally triggered off by pregnancy conditions hence their occurrences during pregnancies. Result in Table 3 shows the physical health problem of the nursing mothers.

Table 2: Group Physical health problems of pregnant mothers.

\begin{tabular}{|c|c|c|c|c|c|}
\hline \multicolumn{2}{|r|}{ Group Physical Health Problems } & Frequency & Percent & Valid Percent & Cumulative Percent \\
\hline \multicolumn{2}{|r|}{ Low physical health problem (0-49\%) } & 107 & 71.3 & 71.3 & 71.3 \\
\hline Valid & High physical health problem ( $50 \%$ and above) & 43 & 28.7 & 28.7 & 100 \\
\hline \multicolumn{2}{|r|}{ Total } & 150 & 100 & 100 & \\
\hline
\end{tabular}

Table 3: Distribution of Physical Health Problems among Nursing Mothers in Abakaliki Urban.

\begin{tabular}{|c|c|c|}
\hline Physical Health Problems & No. of Respondents & Percentage \\
\hline Milk supply problem & 114 & $76.00 \%$ \\
\hline Breast problems & 95 & $63.30 \%$ \\
\hline Abnormal nipple discharge & 89 & $59.30 \%$ \\
\hline Intense breast pain & 81 & $54.00 \%$ \\
\hline Sepsis (fever or drainage) & 66 & $44.00 \%$ \\
\hline Vaginal tear & 65 & $43.30 \%$ \\
\hline Dislocation of the hip & 59 & $39.30 \%$ \\
\hline Diarrhea & 44 & $29.30 \%$ \\
\hline Mastitis & 28 & $18.70 \%$ \\
\hline
\end{tabular}

Majority of the nursing mothers 114 (76.0\%), 95 (63.3\%), 89 (59.3\%) and 81 (54.0\%) have milk supply problem, breast problem (engorgement \& abscess), abnormal nipple discharge and intense breast pain. Other physical health problems of the nursing mothers are 66 (44.0\%) sepsis (fever or drainage), 65 (43.3\%) vaginal tear and $59(39.3 \%)$ dislocation of the hip. However, the physical health problems that least affect the nursing mothers were diarrhea 44 (29.3\%) and mastitis 28 (18.7\%). The result as further shown by the logistic regression analysis also indicated the group physical health problem among $0-49 \%$ of the nursing mothers with low physical health problem to be $56(37.3 \%)$ while $50 \%$ and above of the women had high physical health problem 79 (52.7\%) The result of the study did not come as a surprise as Brown and Lumley [11] had earlier reported post-natal health problems such as depression six to seven months post-partum among some of group reproductive women under their investigation. The authors also found urinary incontinence, back pain, sexual problems, more cough, colds and minor illnesses than usual. The Authors however, found these to be significantly associated with poorer levels of emotional wellbeing. Figure 1 shows the social health problems of pregnant mothers in Abakaliki Urban of Ebonyi State. Majority $133(88.70 \%), 116(77.30 \%)$ and $94(62.70 \%)$ were difficulty in copying with pregnancy, inadequate provision of health facilities, and inadequate provision of basic social amenities. However, few $65(43.30 \%), 48(32.00 \%)$ and $30(20.00 \%)$ are violence, divorce and widowhood. Further regression analysis showed group $0-49 \%$ of pregnant women with low social health problem to be $14(9.3 \%)$ while $50 \%$ \& above of the women indicated 124 $(82.7 \%)$ high social health problem. The result of the study is in line with Blog Network [12] where it was posited that in as much as reproductive women 's health is affected by their biology, it is also affected by their social conditions such as poverty, availability of social amenities, employment and spousal relationship. [6,13] also in accordance with the present study reported female 


\section{Global Journal of Reproductive Medicine}

genital mutilation, sexual abuse and domestic violence as social health problems experienced by nursing mothers and further reported that worldwide, about $10 \%$ of pregnant women and $13 \%$ of nursing mothers experience depression and are higher in the developing countries with $15.6 \%$ during pregnancy and $19.8 \%$ after childbirth. The results are expected because a good home and society with adequate social amenities, comforts of life, cordial inter-spousal relationships and family love will make life worthwhile for pregnant women and thus hinder occurrence of any sickness. Bar chart showing the Social Health Problem of the
Nursing Mothers Key:

a) Inadequate provision of basic social amenities

b) Inadequate provision of health facilities

c) Lack of social acceptance

d) Timidity while breast feeding

e) Isolation of breastfeeding mothers

f) Abandonment by spouse

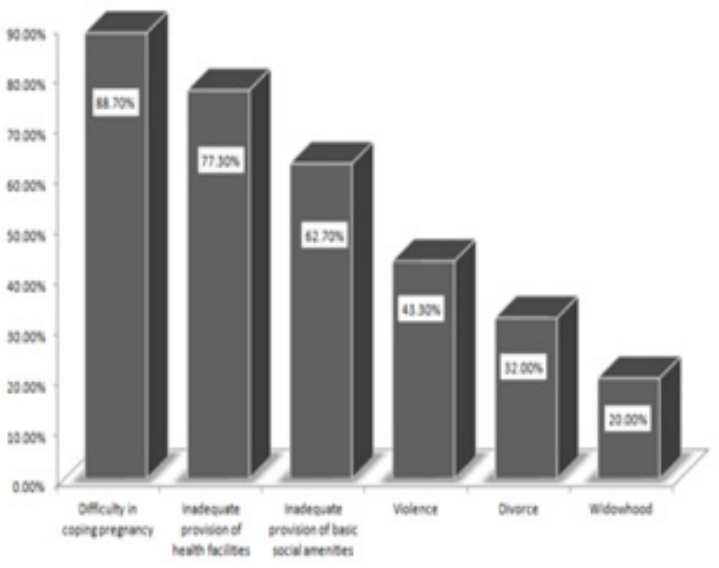

Figure 1: Bar chart distribution of social health problems among selected pregnant mothers in Abakaliki urban of Ebonyi state.

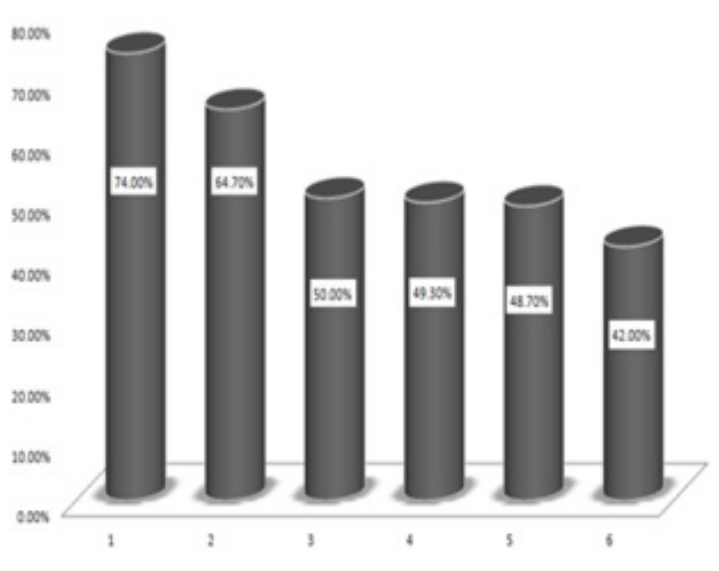

Figure 2: Distribution of social health problems of nursing mothers in Abakaliki urban of Ebonyi state.

Figure 2 shows the social health problems of nursing mothers in Abakaliki Urban of Ebonyi State. Majority 111 (74.0\%), 97 $(64.7 \%)$ and $75(50.0 \%)$ are inadequate provision of basic social amenities, inadequate provision of health facilities, and lack of social acceptance of breastfeeding. However, minor 74 (49.3\%), $73(48.7 \%)$ and $63(42.0 \%)$ are timidity, isolation of breastfeeding mothers and abandonment by spouse. Further regression analysis with $0-49 \%$ of the nursing mothers have low social health problem $13(8.7 \%)$ while $50 \%$ \& above of the women indicated 118 (78.7\%) high social health problems. The result of this investigation is in accordance with [32] finding that socio-environmental conditions including poverty, inadequate provision of social amenities such as insufficient transport system, gender bias, lack of social acceptance, poor working condition are positively related to maternal health 


\section{Global Journal of Reproductive Medicine}

complications and as such calls for urgent policy intervention to address social and work-related pressures on potential mothers. Figure 3 shows the economic health problems of pregnant mothers in Abakaliki Urban of Ebonyi State. Majority 107 (71.3\%) indicated increased cost of medical service. Others, 97 (64.7\%) were lack of income, 92 (61.3\%) were lack of employment and 81 (54.0\%) indicated poverty as their economic health problem. Further regression analysis with $0-49 \%$ of the pregnant mothers have low economic health problem $18(12.0 \%)$ while $50 \%$ \& above of the women indicated $121(80.7 \%)$ high economic health problems. The result of the study was expected as many previous studies had associated most of the factors indicated by the findings as source of burden to reproductive mothers' health. Blog Network [12] revealed that women have traditionally been disadvantaged in terms of economic and social status and power which in turn reduces their access to the necessities of life including health care [16] held that health status of women declines as their socioeconomic status including income, declines. Mcbarnette noted that relationship existed between poverty and several indicators of reproductive health status of women [17] also indicated crucial role of economic factor in influencing the Polish women's health. It was found by the same study that reproductive women whose financial position was poor indicated more likelihood to assess their health as less than good to suffer from respiratory, neurotic and circulatory system's diseases [33] equally found that indicators of poor economic health of the mothers include lack of employment and low educational level especially among young reproductive mothers. Figure 4 shows the economic health problems of nursing mothers in Abakaliki Urban of Ebonyi State. Majority 122 (81.3\%) and 108 (72.0\%) indicate increased cost of medical services as their economic problem. Others, 92 (61.3\%) are increased transportation for fares for postnatal cares, and 77 (51.3\%) are inadequate money faring. Further regression analysis with $0-49 \%$ of the nursing mothers have low economic health problem $6(4.0 \%)$ while $50 \%$ \& above of the women indicated 123 $(82.0 \%)$ high economic health problems. The results as shown in Figure 4 were expected based on previous findings by Adenike, Edewor and amoo [32] where it was explicitly shown that socioenvironmental factors for instance poverty is closely related with maternal morbidity. This reason undoubtedly must have accounted for the majority 122 (81.3\%) attributed to increased cost of medical services as shown by the Figure 4. Many of the women's problems arose from their financial incapacity to foot their medical care bills. Table 4 shows that women with higher age (25-30yr: AOR=.045, 35-40yr: AOR=.281)who reside in the rural (AOR=.672), are less likely to be associated with high health problems during pregnancy compared to women of lower age, and who resides in the urban. Table 5 further reveals that women that have 3-4 and more than 5 children are 8.908 and 5.342 times respectively more likely to have high health problems than those with 1-2 children. However, the respective confidence interval and P-value for age, location and parity indicates that these variables are not significantly associated with high health problems during pregnancy. Consequently, the null hypothesis of no significant association is hereby accepted for location and parity.

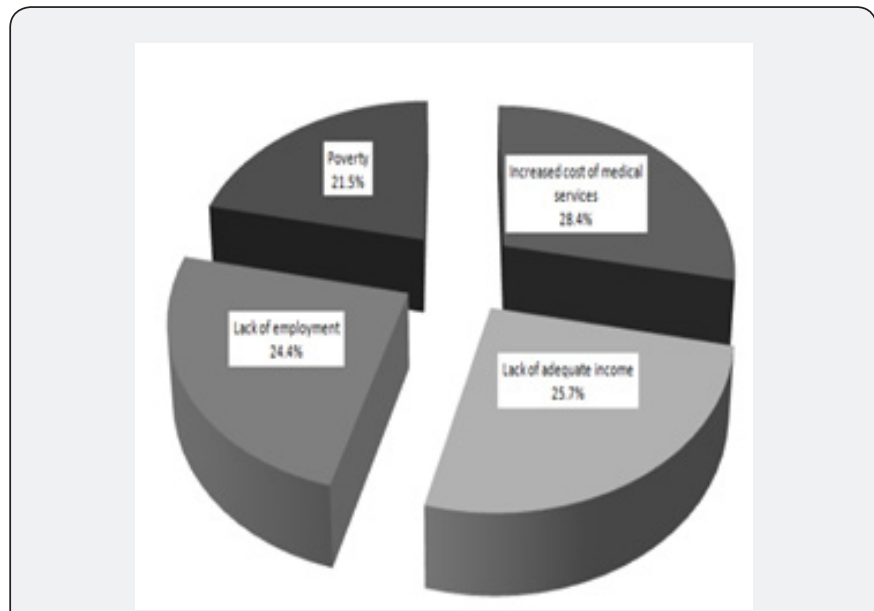

Figure 3: Distribution of economic health problems of pregnant mothers in Abakaliki urban of Ebonyi state using pie chart.

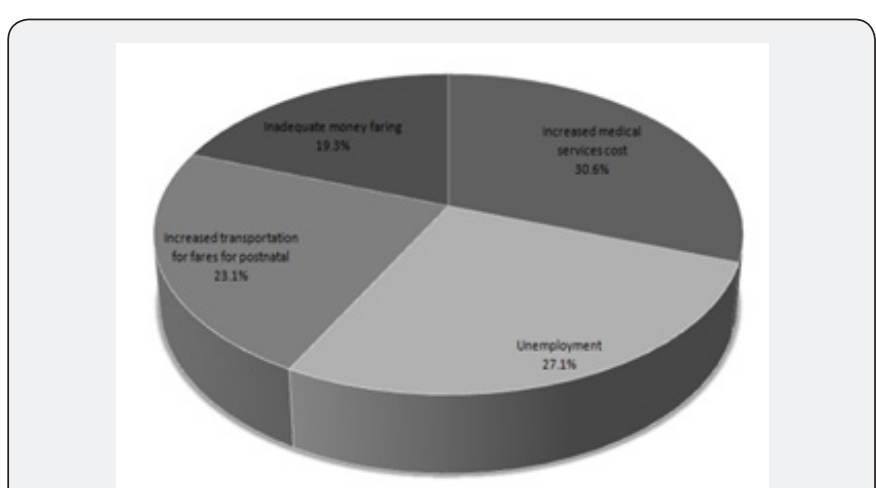

Figure 4: Distribution of economic health problems of nursing mothers in Abakaliki urban Using pie chart.

\section{Implication for Reproductive Health Education}

Based on the findings of the study, it is obvious that the reproductive women investigated are confronted by numerous health challenges ranging from physical health challenges to social and economic health problems. As reviewed, the various health problems whether regarded as major or minor can be hurtful to the women as well as her spouse, children and the entire society. This state of affair suggests urgent preventive interventions geared towards reducing the prevalence of the health problems or at least bring them to the barest minimum among the women. Be it as it may, this aim may not be achieved without firstly offering factual information to the reproductive mothers on the incidence of health problems, their susceptibility, vulnerability and severity of such problems if allowed to escalate. Inculcatig health ideas into the women can only be done through health education targeted at the reproductive mothers. Health education is defined as a means of assisting people to acquire information, knowledge, attitudes and 


\section{Global Journal of Reproductive Medicine}

skills for effecting desired behaviors. It is a means of sensitizing and influencing individuals to acquire desireable knowledge, attitude and behaviors that are favorable to health and reject those that are damaging to individual, family and community health [34]. As it concerns the reproductive mothers, health education can indeed be a tool with which to educate and disseminate relevant health knowledge as well as skills towards attainment of optimal health among the women. They can be informed through health education on the various physical, social and economic health problems, their consequences to pregnancy and infant children [35]. Information on the causes, signs and symptoms, control and importance of prompt medical treatment in times of occurrence can be presented to the reproductive women. Such pieces of information are necessary which every pregnant and nursing mother should be imbibed with. From the findings of the study, it implies also involving the reproductive mothers although minor in number with HIV/AIDS in the health education intervention by informing them on their heightened risk of developing more health problems than the rest of the groups and as such letting them know the need to adopt all possible preventive measures [36]. In order to reach out to massive number of reproductive women, health education intervention can be mounted in churches, women associations, women community meetings, antenatal and post-natal visits. The reproductive mothers ought also to be informed through such women for the connection between most of the health problems and childbearing and as such can be informed about family planning including artificial and natural methods in order to make more informed decisions. This will reduce their vulnerability to the health problems. Other activities to be included in reproductive mothers' health education should include safe motherhood, post- abortion care, female genital mutilation, reproductive tract cancers, and prevention of motherto--child transmission of HIV. By the findings, it then implies urgent call for active involvement of all health care delivery team especially health educators whose tasks are primarily to carry out health education interventions in order to promote, maintain and improve the reproductive women's' health.

Table 4: Group Physical health problems of nursing mothers.

\begin{tabular}{|c|c|c|c|c|c|}
\hline \multicolumn{2}{|c|}{ Group Physical Health Problems } & Frequency & Percent & Valid Percent & Cumulative Percent \\
\hline \multirow{2}{*}{ Valid } & Low physical health problem (0-49\%) & 56 & 37.3 & 41.5 & 41.5 \\
\cline { 2 - 5 } & High physical health problem (50\% and above) & 79 & 52.7 & 58.5 & \\
\cline { 2 - 4 } Missing & Total & 135 & 90 & \multirow{2}{*}{100} & \\
\cline { 2 - 5 } & \multirow{2}{*}{ Total } & System & 15 & 10 & \\
\cline { 2 - 5 } & & 150 & 100 & & \\
\hline
\end{tabular}

Table 5: Summary of Logistics Regression on Health Problems of Reproductive Mothers in Abakaliki Urban of Ebonyi State.

\begin{tabular}{|c|c|c|c|c|c|}
\hline Variables & AOR & \multicolumn{2}{|c|}{ 95\% C.I for AOR } & P-value & Dec \\
\hline \multicolumn{6}{|c|}{ Age: } \\
\hline $15-20 y r s$ & & & 0.429 & & \\
\hline $25-30 y r s$ & 0.045 & $.45-.001$ & & 0.115 & S \\
\hline $35-40 y r s$ & 0.281 & $0.12-6.788$ & & 0.435 & NS \\
\hline $41-49 y r s$ & 0.147 & $0.006-0.704$ & & 0.243 & S \\
\hline \multicolumn{6}{|c|}{ Location: } \\
\hline \multicolumn{6}{|l|}{ Urban (ref) } \\
\hline Rural & 0.672 & $.086-5.244$ & & 0.704 & NS \\
\hline \multicolumn{6}{|c|}{ No of children: } \\
\hline 1 - 2 children & & & 0.416 & & \\
\hline $3-4$ & 8.908 & $.170-5.06$ & & 0.207 & NS \\
\hline$>=5$ & 5.342 & $.262-3.891$ & & 0.276 & NS \\
\hline
\end{tabular}

\section{Conclusion}

Based on the findings, it can be established that reproductive mothers comprising pregnant and nursing mothers are faced with numerous health problems classified as physical, social and economic health problems. While some are considered major based on the number and percentage of those having it, others are considered minor. Regardless of the number and prevalence, the health problems are challenging enough and capable of endangering a reproductive woman's life. Nevertheless, with proper health education intervention in place, the health problems can be surmounted or at least reduced to a very insignificant level. Thus we recommend that: 
i. Government at all levels in collaboration with the ministry of health should organize periodic health education seminars for reproductive mothers during ante natal and post-natal visits in order to reach out to the reproductive women and sensitize them on all relevant information concerning the prevailing health problems.

ii. The federal government in collaboration with NonGovernmental Organizations (NGOs) should train more health educators to be involved in the health education intervention so as to ensure wider coverage of rural and urban areas.

The government at all levels should offer free medical cares for every pregnant and nursing mother so as to reduce the difficulty and financial crisis they encounter seeking for medical cares.

\section{References}

1. WHO (2018) Promoting health through the life course. Ten top issues for women health.

2. (2018) United Nations Population Information Network.

3. Human Rights Matrix (2018) Human rights.

4. Mormon Org (2018) The role of mothers in nurturing and teaching.

5. Salmon N (2016) The top 12 duties of a mother/ family by God's design.

6. Fathalla (2018) Issues in reproductive health, p. 3.

7. Centre for Disease Control (2018) Pregnancy Complications.

8. Betond B (2018) What is physical health/ problem.

9. Miranda H (2007) Women's pelvic health problem.

10. Baylor S, White H (2017) Physical Health Problems of mothers.

11. Brown B, Lumley L (2015) Blog: An IInt J Gynecol Obstet 107(10).

12. Blog Network (2018) Physical health problems after childbirth and material depression at 6 to 7 months post-partum 107: 10 .

13. Purnima L (2017) What are the major social problems related to women Quora.

14. WHO (1990) The health of mothers and children: key issues in developing countries. In Point Fact (70):1-4.

15. Lewis J, Doshi M, Dyanira A, Refeat A (2018) The health of women/ mothers and children.

16. Mcbarnette L (1987) Women and poverty: the effects on reproductive status.
17. Wroblewska W (2002) Women health status in Poland in the transition to a market economy. Soc Sci Med 54(5):707-726.

18. Asifa B (2015) Effects of poverty on women health in Khewra $\mathrm{CiH}$, Pakistan. Coalition of national health education (2018). What is Health Education.

19. Parlac (2018) 5 surprising health challenges of aging.

20. Yurcaba J (2019) The most common health concerns in 20, 30 and beyond.

21. Khadidiatou N, Erin P, Dienebe O, Mobley A, Babalola S (2018) High risk advanced maternal age and high parity pregnancy: tackling a negleted need through formative research and action. Glob Health Sci Pract 6(2): 372-383.

22. Spence NJ (2015) The long-term consequences of childbearing; physical and psychological wellbeing of mothers later in life. Res Aging 30(6): 722-751.

23. ACOG (2014) Health disparities in rural women.

24. Schirnding YV, Mulholland C (2001) Health in the context of sustainable development. WHO document.

25. Maternity Worldwide (2020) The sustainable development goals (SDGs).

26. Tezera T (2015) The economic and social impacts of material death.

27. Iwuagwu T, Ofucbe J (2011) Physical and emotional health problems of pregnant women attending antenatal clinics in Nsukka health districts, Enugu State. NJHE 17 (1): 117-133.

28. Nworgu BG (2006) Educational research: Basic issues and methodology ( $2^{\text {nd }}$ edn.) University Trsur Publishers, Nsukka, Nigeria.

29. Ogbazi JN, Okpala J (1994) writing research report: Guide for researchers in education, the social sciences and the humanities. Enugu, Nigeria.

30. Derek (2002) Every woman: A gynecological IJ guide for life. spectrum Book Limited., Ibadan, Nigeria.

31. Okereke P (2005) Obstetics and the newborn. WB Saunders, London.

32. Adenike EO, Edewor PA, Amoo EO (2014) Working conditions and material health challenges in Lagos State, Nigeria. Res hum soc sci 4(9).

33. Herard (2013) Does Poverty affect women more.

34. Omaka LN (2004) Teaching of health education in schools: a necessary foundation for nation building HMEJ 8(1): 52-54.

35. Aneifork M (2004) The health education teacher and the burden of exotic Diseases: in polication for nation building. HMEJ 8 (8):76-82.

36. Omaka, LN En CO (2013) Reducing the burden of malaria on vulnerable groups. The role of health education. NJHE 17(1): 48-63. 
(C) (i) This work is licensed under Creative
Your next submission with Juniper Publishers will reach you the below assets

- Quality Editorial service

- Swift Peer Review

- Reprints availability

- E-prints Service

- Manuscript Podcast for convenient understanding

- Global attainment for your research

- Manuscript accessibility in different formats ( Pdf, E-pub, Full Text, Audio)

- Unceasing customer service

Track the below URL for one-step submission https://juniperpublishers.com/online-submission.php 